\title{
SYNESTHETIC ARTISTIC PERCEPTION IN THE ERA OF POST LITERACY
}

\author{
Gudova Margarita $^{1 *}$, Lisovetc Irina ${ }^{2}$ \\ ${ }^{1}$ Prof. Dr., Ural Federal University, Russia, MargGoodova@gmail.com \\ ${ }^{2}$ Prof. Dr., Ural Federal University, Russia, irlisovec@yandex.ru \\ ${ }^{*}$ Corresponding author
}

\begin{abstract}
In the era of post-literacy, the development of information technology and the technological basis of art as well as the mechanisms of not only artistic creativity, but also its perception, change. The transformation peculiarities of artistic perception of the new polymorphic and multimedia art require their scientific and theoretical comprehension in the conditions of post-literacy that have developed in the last 50 years.

In this case, we are interested in the nuances characterizing the changes in artistic cultural perception caused by the emergence of new polymorphic texts in their linguistic nature and originated in the process of synesthetic artistic creativity with the use of multimedia technologies.

In the process of analyzing the characteristics of the transformations of contemporary artistic perception, the authors rely on the principles of the synesthetic approach, formulated in its foundations by the outstanding Russian scientist Bulat Galeev as well as the historical and morphological approach to art developed by another respected Russian philosopher, Moses Kagan.

The authors reveal such factors of development in art languages and art perception as the culture-centrism of contemporary art practices, the influence of virtual reality technology and the synesthetic sensuality of audiences.

During the research, it was established that new artistic languages are formed on the basis of the classical art languages, through their synthesis, synesthetic interaction, or an intermediate combination of both. The artistic perception of projects created with the help of new artistic languages, complex perceptual associativity, and imagination allow the synesthetic perception of polymorphic and multimedia texts.

In conclusions, the authors contend that perception of third-millennium art presupposes a synesthetic dominant expressing the features characterizing the transformation of contemporary art languages.
\end{abstract}

Keywords: post-literacy era, new artistic languages; polymorphic texts, artistic perception, synesthetic sensuality 


\section{INTRODUCTION}

In recent years, more and more phenomena have arisen that puzzle the artistic communication addressesthe public and researchers with language and the form of their utterances. Actual art, using objects of daily life as means of expressiveness, maximally transforming the human body in combination with the possibilities of information technology or social practices, turns out to be an incomprehensible text claiming to have artistic status. The townsfolk, as a rule, do not perceive such texts and refuse artistic communication. For specialists, the scientific explanation of these phenomena falling out of the usual artistic communication becomes a socially demanding task.

Questions such as how and why, for which purposes are diverse and heterogeneous because of the texts and languages combined in one artistic project. What are the advantages of the utterances created with the help of synthetic, polymorphic languages of art? To what transformations of artistic communication do they lead?

\section{METHODOLOGY}

In the search for ways to explain the "communication gaps" in experimental art practices, let us turn to contemporary aesthetic thought. As the Serbian aesthetician M. Shuvakovich asserts, "Contemporary art in many of its manifestations rejects traditional and monomorphic artistic languages, it does not work anymore solely with visual or auditory, or volumetric-linear, or verbal images" (Shuvakovich, 2008, 80). In contemporary art, there is an ongoing experiment on new languages of artistic expression and destruction of the conventional boundaries of artistic communication that limit authorial creativity and the meaningful cocreation of the addressee within the limits of one particular art form.

B. Groys, another famous researcher of contemporary artifacts, says today's contemporary art "demonstrates the way modernity represents its essence. The act of presenting it." In the opinion of this researcher, it happens in such forms that "every creative act turns into an iconoclastic gesture" (Groys, 2006, 21). It seems that the origins of this radical perception and understanding have not been sufficiently described in terms of the changes taking place in the cultural system as a whole.

According to L. Zaks, an authoritative Russian esthetician, the essential factors underlying these transformations are the changes in the value profile of culture systems. Modern culture, as a system aimed at solving stabilization problems, reflects them upon itself. This constitutes the culture-centrism of modern consciousness especially concerning its artistic form that, in turn, generates the languages and texts of modern arts. As L. Zaks contends, "This art's innovation is that cultural artifacts - things, places, environments, people's actions and gestures, virtual digital products - serve as the representatives of culture" (Zaks, 2017, 25). All the above phenomena become elements of the language of contemporary art form, a new artistic reality, obeying the most diverse authorial intentions.

Another factor is the pressure of digital multimedia culture, generated by new virtual reality technologies, on the culture being as a whole. Increased in the emergence of a multimedia highway trend toward the simultaneous combination of several channels of broadcasting, heterogeneous information using a single device is preserved in the world of its existing traditional way, non-digital art. This is affected by the impact of digital technologies and their capabilities to transform multimedia artistic expression by developing contemporary art languages.

The continuing development of art in the synthetic logic of specific artistic languages is a consequence of the influence of the part of the system (artistic language) on the whole system (the world of artistic communication). As is known from various studies of the mechanisms of the development of artistic languages, the logic of the development of artistic languages can be several. The first is the differentiation (analytics) of the languages of the artistic utterance. It manifests itself in the study of atonality, duration, rhythm, and loudness in modern music. In opportunity, there is synthesis when the artist uses one artistic language to embody the effects of another or other languages of art. In this case, we are interested in the logic of synthesis in the development of the language of art.

The third important factor determining the changes in the language of art is the transformation of the artistic communication addressee's sensuality that was formed throughout the 20th century under the influence of technical media. This new sensuality is characterized by multiplicity of channels, instantaneousness, and the integral perception of information. The contemporary art addressee is able to integrate a single text from simultaneously perceived heterogeneous signs and texts of artistic expression in their mind and interpret them in the hermeneutic circle of the artistic culture that he has mastered while reading the peculiarities of intertextuality and intermediately in the perception of each particular work of art. 
The principles of the synesthetic approach to art embodied in artistic practice were formulated in their foundations by the outstanding Russian aesthetician Bulat Galeev. He proceeded from the etymology of the compound word "synaesthesia" - "synestezis", i.e. "Co-sensation," co-feeling, "and also" co-representation "and even" meaning, "interpreting the root of the word" sense "as" sensory, "sensitive "(Galeev, 1987, p.104).

The analysis of changes in artistic perception, its multi-sensory measurement, and transformation of artistic communication as a whole is one of the most important fields of research in modern foreign non-classical aesthetics. During the last congress of the International Aesthetics Association held in Seoul on July 24-29, 2016, entitled "Aesthetics and Mass Culture", a number of researchers addressed these issues.

For instance, Arnold Berleant considered the causes and nature of rejection in reference to the free aesthetic sensibility characteristic of classical art and the possibility of its modern reproduction. On this topic, he insists, "A case is made for the subvention of beauty by appropriating and distorting the capacities of human sensibility in four ways: through gastronomic co-operation, technological co-optation, [and] emotional cooptation. By appropriating, controlling, and limiting the capacities of human sensibility, these forms of cooptation undermine the free sensibility that is the heart of aesthetic pleasure, thus subverting the possibilities of aesthetic appreciation" (Berleant. 2016, p.183). On the other hand, Eom Jonga Tijm examined the visual perception peculiarities in Korean contemporary art, about which he noted synesthesia and the ability to absorb various types of artistic creativity in a variety of combinations and forms of existence (Eom, 2016, p.83)

Multisensory measurements in the perception of motion pictures «in the age of mechanical reproduction» (Walter Benjamin's, 1936) had discussed in report Mary Wiseman on the Round Table "The role of the nonvisual in contemporary art: taste, smell, kinesthesis, and touch" (Wiseman,.2016, p.35).Thus, aesthetic research recognizes the radical change in the interaction of art and the public in contemporary culture and concludes that the perception of art as a specific mental activity in the culture of post-literacy in the radical transformation of language and the extra-institutionality of the domain of being artistic implies a reliance on a new culture artistic perception in its operational and substantive differentiation.

\section{RESULTS}

Only after considering the key to understanding the causes and conditions for the formation of polymorphic art languages, the factors related to the systemic cultural-centric functioning, the dominance of technology in creating virtual reality as well as the formation of the new addressee's sensuality, it is possible to approach the genesis of artistic synesthesia from a scientific point of view.

First, the roots of artistic synesthesia are closely connected with the development of new art languages. In each separate art form, synthesis, based on the dominant language of this art form, occurs to which elements of other artistic languages may be added. Another manifestation is the use of an additional artistic language or various languages of corporeality, everyday life, informatics, and technology.

Second, the internal interaction of the languages of art gives birth to the artistic synesthesia phenomenon. Modern art is synesthetic; that is, it absorbs various types of artistic creativity in a variety of combinations and forms of existence. Such internal changes in the artistic language assume the simultaneous corresponding activation of several perceptual abilities for understanding.

Modern art breaks the boundaries between the artistic and non-artistic worlds, transforms languages, of Third, modern art breaks the boundaries between the artistic and non-artistic worlds for it transforms languages and disorients perception, but also expects a new audience that would be able to understand it despite its strangeness and shock provoking expression.

Lastly, for a rich artistic communication in the culture of post-literacy, it is necessary to develop synesthetic sensory experiences, the abilities to actively co-operate with the entire diversity of human feelings and understand the diversity of contemporary cultural practices while constantly interacting with them.

\section{CONCLUSION}

Built upon polymorphic languages expressing multidimensionality and a multiplicity of colors reflecting the artist's understanding of the world, art at the beginning of the third millennium apparently refers to a person's inter-sensory feeling and perception of a post-literacy organic culture capable of communicating with all textproducing forms. New artistic languages, formed on the basis of the languages of classical arts, through their synthesis and synesthetic interaction that include intermedia combinations, suggest complex perceptual and interpretive abilities. These abilities include multisensory, perceptual associativity and imagination, all of which allow to synesthetically perceiving polymorphic and multimedia texts. 
To adjust the perceptions of contemporary art is a need directed to the actualization of its syncretic nature only achieved through the cooperation of feelings at various levels favoring awareness of the specific vision inherent in the artist and an understanding of what is not given to ordinary perception. In becoming synesthetic, the person is ready to participate in a dialogue with contemporary art in the mutual enrichment, interpenetration and mutual change in the genres of artistic expression. Therefore, synesthetic sensuality and metacognition become a necessary feature of contemporary art perception.

It is for such a sensually developed audience who owns culturally different languages, is able to constantly change and vary the languages of utterance and interpretation that contemporary art is produced. Art still counts on the interested interlocutor who can become an active accomplice in what is happening. Art is made for such a reader, spectator, and listener because he is also an integral part of the culture of postliteracy.

\section{REFERENCE LIST}

Berleant, A. (2016) The co-optation of sensibility and the subversion of beauty. Abstract book "Aesthetics and Mass Culture".

Eom, J. (2016). Art and visual perception: its play on visual perception in Korean contemporary art. Abstract book "Aesthetics and Mass Culture".

Galeev B.M. (1987) The problem of synesthesia in aesthetic.

Groys B. The topology of contemporary art. Art Journal, Vol. 61-62. http://xz.gif.ru/numbers/61-62/topologiya

Zaks L.A. (2017). Revolutions in Culture as a foundation of modern artistic world. Proceedings of XI Kagan's readings, the conference "Current artistic practices and their theoretical reflection".

Shuvakovic M. (2008). Epistemology of Art. Critical design for procedures and platforms of contemporary art education.

Wiseman, M. (2016). Kinesthetic and tactile responses to work of art. Abstract book "Aesthetics and Mass Culture" 